TP Periodica Polytechnica

Mechanical Engineering

60(4), pp. 233-237, 2016

DOI: 10.3311/PPme.8978

Creative Commons Attribution (i)

RESEARCH ARTICLE

\section{Numerical Study of Internal Radius Effect on Mechanical Behavior of P265GH Material}

\author{
Mohammed Lahlou ${ }^{1 *}$, Nadia Mouhib ${ }^{1}$, Hanaa Ouaomar ${ }^{1}$, \\ Abdelilah Hachim², Mohamed Elghorba ${ }^{1}$
}

Received 05 January 2016; accepted after revision 30 August 2016

\begin{abstract}
In metallic structures, cracks are mostly initiated at geometric discontinuities of notches or defects. The geometric parameters and discontinuities govern cracks initiation or propagation and therefore affect the resistance of structures during their use. In industry, for economic or security reasons it is seek to know the degree of defects harmfulness and residual life time of structures; This requires the development of models based on fracture mechanics.

The objective of this paper is to establish a numerical finite element modeling for a bent specimen using CASTEM2013 computer code. The studied material is P265GH steel commonly used in sheet form in boilers and pressure vessels.

The results show that the propagation velocity of crack and stress concentration coefficient increases by increasing the length of the crack and the diameter of the structure.
\end{abstract}

\section{Keywords}

pressure vessels, Finite element model, stress concentration coefficient, notch, Stress intensity factor

\footnotetext{
${ }^{1}$ Laboratory of Control and Mechanical Characterization of Materials and Structures, National Higher School of Electricity and Mechanics, Hassan II University, BP 8118 Oasis, Casablanca, Morocco

${ }^{2}$ ISEM/Higher Institute of Maritims Studies, Laboratory of Mechanics, Km 7 Road El Jadida, Casablanca, Morocco

*Corresponding author, e-mail: Lahloumohammed89@gmail.com
}

\section{Introduction}

Gas storage devices are regulatory. Their construction is governed by building codes and the ministerial regulations. It involves various stakeholders: manufacturer, operator and inspector $[1,2]$.

In recent years the consumption growth of LPG "liquefied petroleum gas" led to the construction of many storage tanks in our country. Competition in this area is becoming more severe and the responsibility of control and inspection organizations is undeniable to ensure the safety of these equipments $[3,4]$.

On the microscopic scale, any material has a defect (inhomogeneities, inclusions, manufacturing defects, etc.) and any mechanical part could present section changes or rough surface states. Since these conditions favor the appearance of stress concentrations, we should often consider the possibility of crack initiation as well as its propagation when calculating a structure. For this reason, the designers of structures or any element subjected to cyclic loadings should not only take into account the possibility of cracking, but also estimate the velocity of crack propagation, to ensure that these cracks do not reach the critical length, which will inevitably lead to failure [5].

The behavior simulation with FEM has been presented by many authors with the aim to improve the knowledge of predicting trends. HAKIMI [6] generalized the study of cylindrical and spherical shells under pressure. He proposes an approach based on the stress intensity factors $\mathrm{K}$ and $\mathrm{J}$ integral obtained numerically or by simplifying methods for semielliptical cracks internal or external, longitudinal or circumferential. SAFIH [7] studied numerically the harmfulness of semi-elliptical circumferential cracks and in an axisymmetric cylindrical shell with a thickness transition. H. Yoshihara [8] presented the critical stress intensity factor on SENT specimen. HADDAD [9] use the stress distribution at the head of a short crack emanating from a notch, to establish the boundary conditions between the stress concentration factor theory of a blunt cut and that an acute notch. RAHMAN [10] showed that the integral $\mathrm{J}$ is the parameter of the elastoplastic fracture mechanics which characterizes the initiation and propagation of the instability of cracks in ductile materials. Indeed, the presence of a notch in a 
structure proves more dangerous than just mechanically reducing the cross section supporting the force transmitted. Harmfulness of notches depends on their size and also their geometric parameters, such as radius and angle notch. A change in a section of part caused by the presence of a notch is altered to the uniform stress distribution and to appear locally stress peaks. The local concentration of stress is measured using the coefficient of stress concentration $\mathrm{Kt}$.

The finite element method adopted in this paper is the most used for real applications to provide a robust solution for most industrial problems.

In the present article, the $\mathrm{P} 265 \mathrm{GH}$ steel used in pressure vessels, and its current specifications, are introduced first. The tensile properties for selected steel are then determined. A numerical finite element modeling based on the tensile properties has been developed.

\section{Experimentation}

To extract the mechanical characteristics of the P265GH steel used in our program, tensile tests on standard specimens (Fig. 1) were conducted in different directions of rolling (longitudinal and transversal). The test curves showing the stress versus strain are given in Fig. $2[11,12]$ :
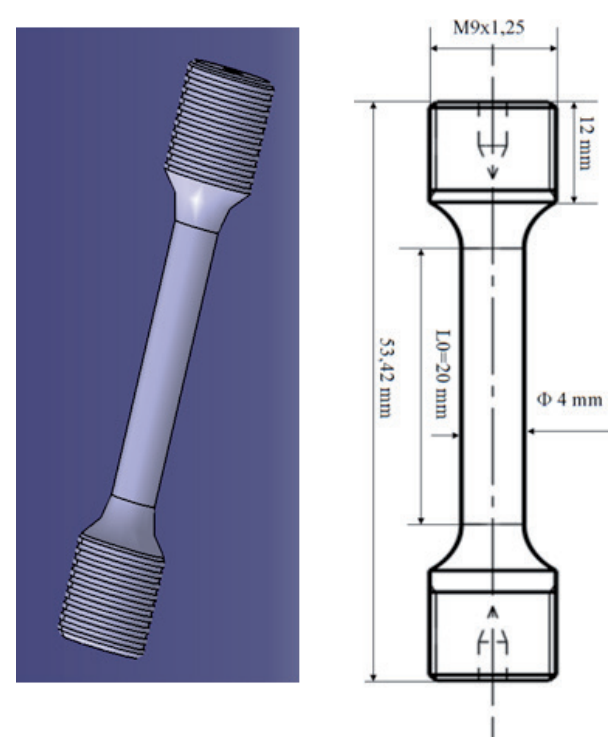

Fig. 1 Dimensions of the standard test specimen

By comparing the mechanical characteristics of specimens in both rolling directions, it is found that there is a negligible difference between tensile test curves. The mechanical characteristics of $\mathrm{P} 265 \mathrm{GH}$ steel, at the ambient temperature, are reported in the Table 1.

We notice that the elongation is about $35 \%$, which is higher than $14 \%$ required by the CODAP [13]. Therefore, this P265GH steel used is well adapted for pressurized structures.

\section{Numerical modeling}

The calculation code Cast $3 \mathrm{~m} 2013$ [15] is used to construct a finite element model in order to analyze the behavior of curved specimen with an interior notch (V) under constant internal pressure. In what follows, we describe FE modeling.

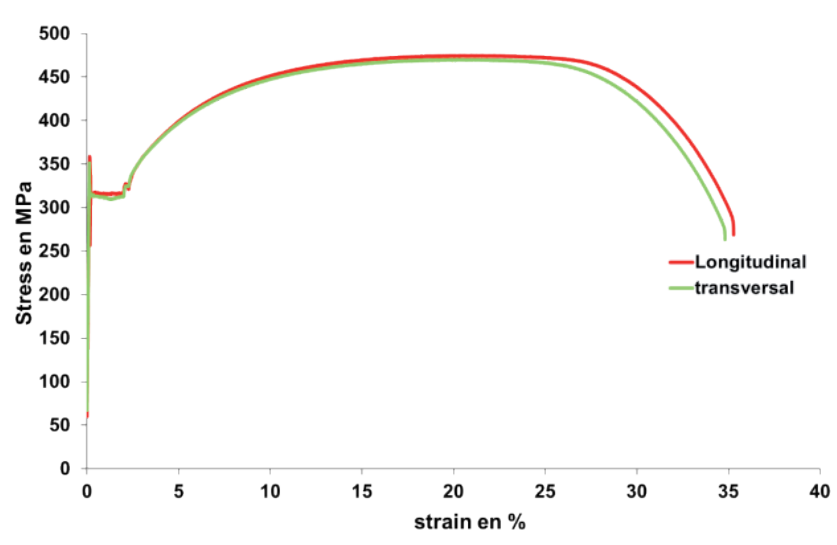

Fig. 2 Stress strain curve test

Table 1 Mechanical properties of the material

\begin{tabular}{lllll}
\hline $\begin{array}{l}\text { Young's } \\
\text { modulus }\end{array}$ & elastic limit: & $\begin{array}{l}\text { Breaking } \\
\text { stress: } \sigma \mathrm{g} \\
\mathrm{E}(\mathrm{MPa})\end{array}$ & $\begin{array}{l}\text { Elongation } \\
\%\end{array}$ & $\begin{array}{l}\text { Poisson's } \\
\text { ratio } v\end{array}$ \\
\hline 2.105 & 320 & 470 & 35 & 0.3 \\
\hline
\end{tabular}

\subsection{Geometry}

The geometry and dimensions of the studied specimens are shown in Fig. 3 and Table 2.

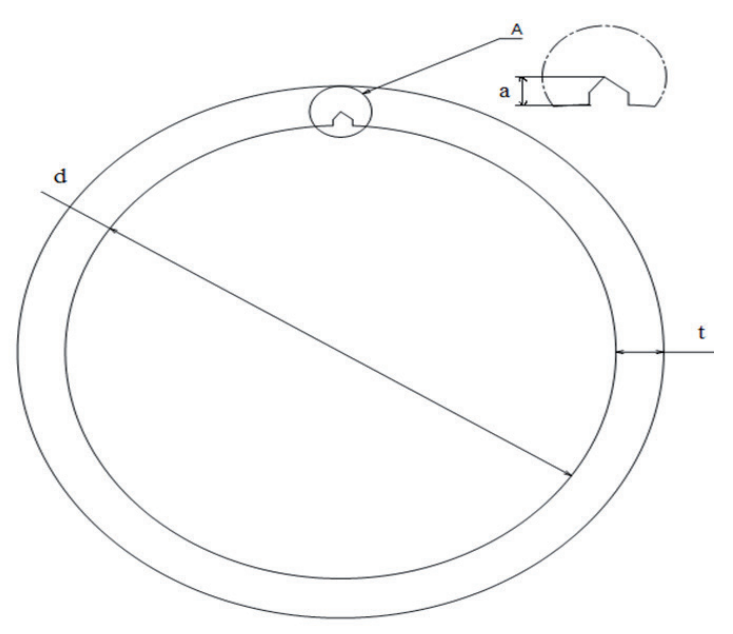

Fig. 3 The geometry and dimensions of the studied specimen

Table 2 The dimensions of the specimen

\begin{tabular}{lll}
\hline Symbol & Description & Dimensions $(\mathrm{mm})$ \\
\hline $\mathrm{t}$ & thickness & 10 \\
$\mathrm{~d}$ & diameter & $100,200,400,1000$ \\
$\mathrm{a}$ & notch length & $1<\mathrm{a}<9$ \\
\hline
\end{tabular}




\subsection{Mesh, boundary conditions and Loading}

By taking into consideration the symmetry of the problem [15], only half of the studied specimen is discretized. Because the numerical results are intended for analysis of fracture mechanics, special attention is paid to mesh principally in crack and its vicinity (Mesh Refinement using Barsoum elements) [16]. Details of the mesh are illustrated in Fig. 4, Fig. 5 and Fig. 6.

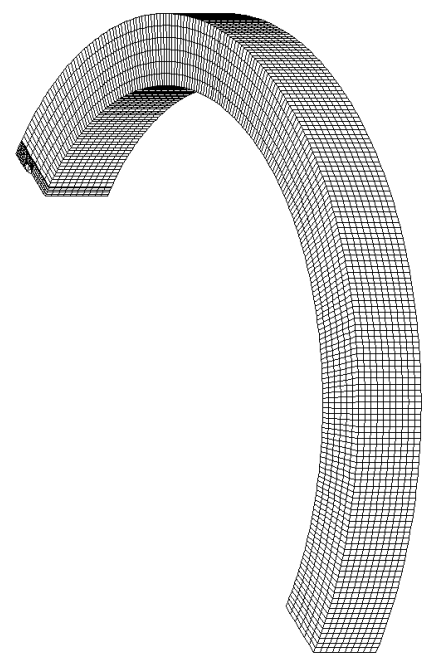

Fig. 4 Mesh (3D)

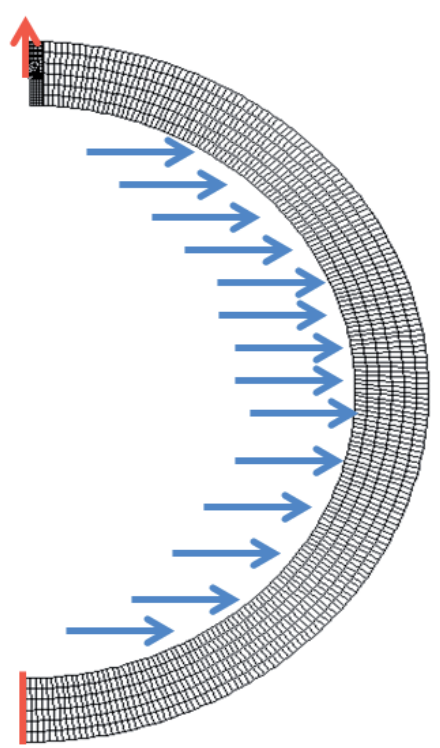

Fig. 5 Mesh (2D)

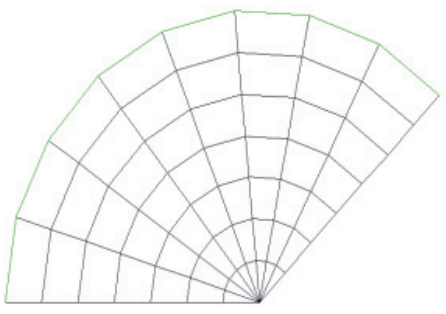

Fig. 6 Mesh in the vicinity of a notch
The selected loads are calibrated in such a way that the applied nominal stress is $114 \mathrm{MPa}$ distributed over the internal face.

The blue arrows are the loads applied and the red lines are lines of symmetry (Fig. 5).

\section{Results and discussion \\ 4.1 Stress concentration coefficient}

The curves in Fig. 7 illustrate the evolution of stress concentration coefficient for different internal radius $(\mathrm{R}=50 \mathrm{~mm}$, $100 \mathrm{~mm}, 200 \mathrm{~mm}, 500 \mathrm{~mm}$ ) depending on the length of notch.

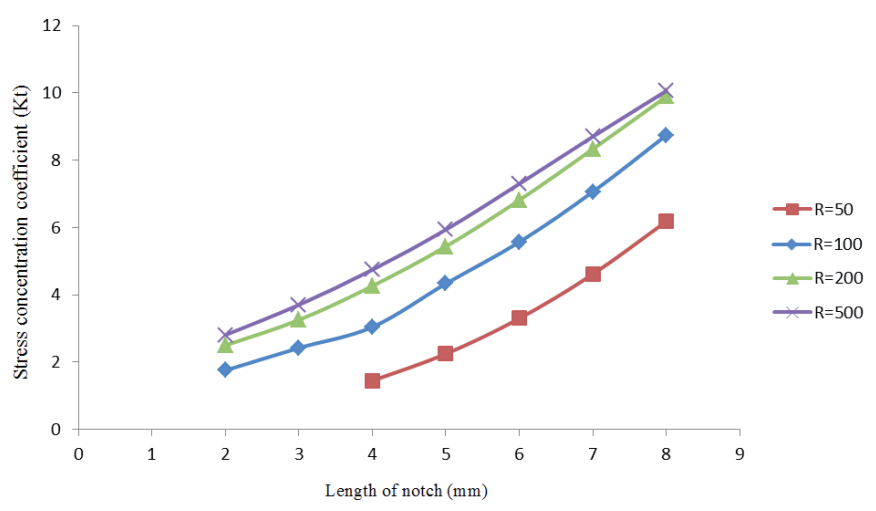

Fig. 7 The Stress concentration coefficient for different internal radius $(\mathrm{R}=50,100,200,500 \mathrm{~mm})$

The analysis of the curves in Fig. 7 shows a significant increase in the stress concentration coefficient as a function of the crack length.

The increase in the radius of the structure induces an increase in Kt, this may be explained by the fact that the increase in radius results in a smoothing of specimen curvature and therefore an increase in the longitudinal stress responsible for the initiation and propagation of the crack.

\subsection{Evolution of the stress intensity factor}

The curves in Fig. 8 are showing the evolution of numerical stress intensity factor $\left(K_{I}\right)$ for different internal radius $(\mathrm{R}=50 \mathrm{~mm}, 100 \mathrm{~mm}, 200 \mathrm{~mm}, 500 \mathrm{~mm})$ depending on the length of notch.

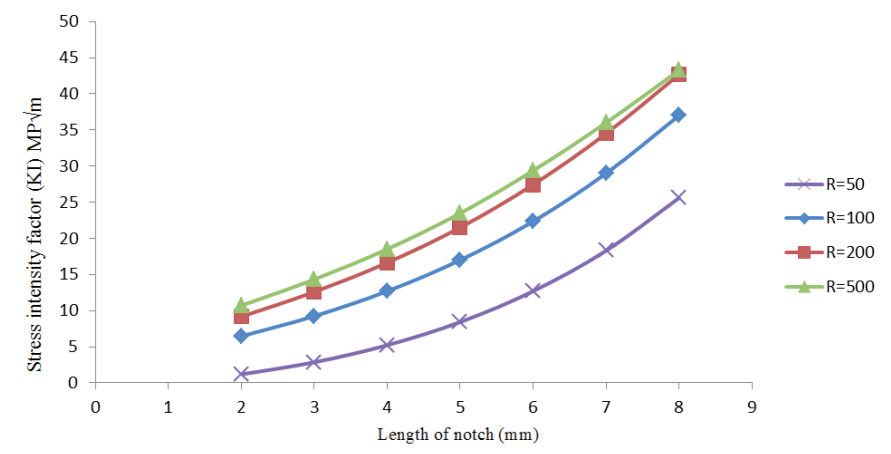

Fig. 8 The Stress intensity factor for different internal radius $(\mathrm{R}=50,100,200,500 \mathrm{~mm})$ 
The analysis of the curves in Fig. 8 shows an important increase in the stress intensity factor depending on the length of the crack.

The increase in the radius of the structure causes an increase of $K_{I}$, therefore crack propagation becomes uncontrollable.

\subsection{Evolution of the crack velocity}

When a crack is formed, its length increases in proportion to the increase of cycles number. The crack velocity is determined by the Eq. (1) [17]:

$$
d a / d N=C\left(K_{I}\right)^{m}
$$

with:

- $d a / d N$ : The crack velocity (where a is the crack length and $N$ is the number of applied cycles)

- $K_{I}$ : stress intensity factor

- $\mathrm{C}=3.6^{*} 10^{-10}$ and $\mathrm{m}=3$ [18]: constants of materials

According to the Eq. (1) it is clear that the crack velocity increases constantly until the sudden break of the part.

Cracking is generally described by the following macroscopic three stages:

a) Stage I (propagation velocity less than $10^{-5} \mathrm{~mm} /$ cycle)

b) Stage II (propagation velocity is between $10^{-5}$ and $10^{-3}$ $\mathrm{mm} /$ cycle)

c) Stage III (rapid spread leading to sudden break than $10^{-3}$ $\mathrm{mm} /$ cycle).

The curves in Fig. 9 are showing the evolution of crack velocity for different internal radius $(R=50 \mathrm{~mm}, 100 \mathrm{~mm}$, $200 \mathrm{~mm}, 500 \mathrm{~mm}$ ) depending on the length of notch.

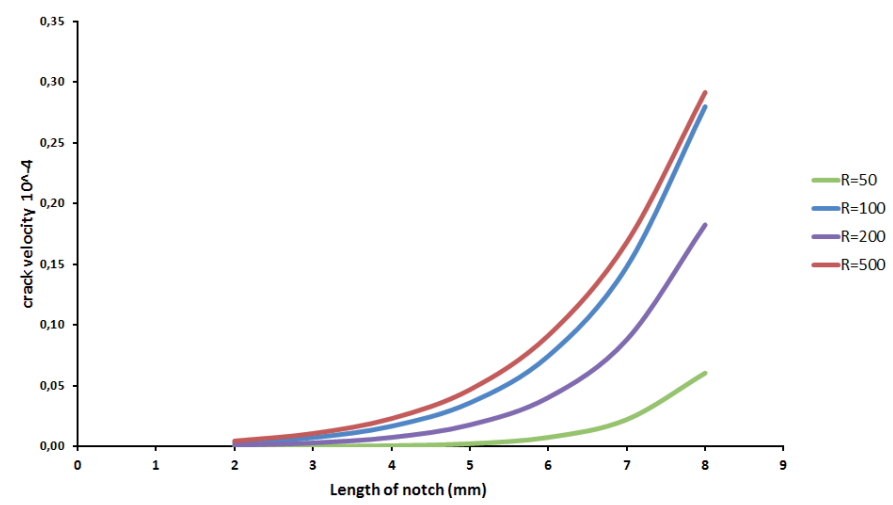

Fig. 9 The crack velocity for different internal radius $(\mathrm{R}=50,100,200,500 \mathrm{~mm})$

It is shown from Fig. 9 that there is a parabolic increase in crack velocity as a function of the crack length.

The increase in the radius of the structure induced crack velocity increase.

The crack velocity remains less than $10^{-3}$ that corresponds to the stage 1 and the beginning of stage 2 .

\section{Conclusion}

In the sectors of unsafe structures such as pressure vessels and in the presence of defect, it is essential to detect precisely the degree of defect harmfulness. Numerical finite element modeling method is an extremely efficient tool to address this issue.

A numerical model using Cast3m 2013 is performed on a bent specimen to study the evolution of the stress intensity factor and the crack velocity along the ligament of the specimen for different internal radius ( $\mathrm{R}=50,100,200,500 \mathrm{~mm})$.

Results show that stress intensity factor and crack velocity increase by increasing internal radius.

The finite element model adopted for this work is commonly used and can be extended to real applications.

\section{References}

[1] "Land Use Planning In Proximity to Natural Gas and Hazardous Liquid Transmission Pipelines in Washington State." Report, June 2006. URL: http://mrsc.org/getmedia/5F52855D-F087-41F6-83C0-839CC088596A/ LandUseGas.aspx

[2] "Safety and Security of Energy Pipelines in Canada: A Report to Ministers." In: Energy and Mines Ministers' Conference, Sudbury, Ontario, Canada, August 2014. URL: https:/www.nrcan.gc.ca/sites/www.nrcan.gc.ca/files/ www/pdf/publications/emmc/14-0177_Pipeline\%20Safety_e.pdf

[3] Barab, J. Wisconsin State AFL-CIO Health and Safety Conference Day, Milwaukee, Wisconsin, Sept. 25, 2009. URL: https://www.osha.gov/pls/ oshaweb/owadisp.show_document?p_table=SPEECHES\&p_id=2011

[4] Hood, A. H. "The Use of Liquified Petroleum Gas (LPG) in Sudan." Report, UNEP, December 2010. URL: http://postconflict.unep.ch/publications/UNEP_Sudan_LPG_use.pdf

[5] Lahlou, M., Rachik, M., Bechtaoui, M., Hachim, A., El Ghorba, M. "Numerical modeling and analytical validation of stress and stress intensity factor for SENT tensile specimen of P265GH steel material." International Journal of Mechanical Engineering (IIJME). 3(4), pp. 42-48. 2015. URL: http://www.ipasj.org/pabstract.php?vol=Volume3Issue4\&J name=4\&pid=IIJME-2015-04-21-9

[6] El Hakimi, A. "Numerical and experimental study of the harmfulness of defects in cylindrical and spherical shells under pressure." $\mathrm{PhD}$ Thesis, University of Technology of Compiègne, June 30, 2006.

[7] Safih, A. "Study of the harmfulness of crack in a cylinder with a thickness transition compared to a straight cylinder." $\mathrm{PhD}$ Thesis, University of Science and Technology of Lille, July 1, 2003.

[8] Yoshihara, H., Mizuno, H. "Mode I Critical Stress Intensity Factor of Medium Density Fiberboard Obtained by Single-Edge Notched Bending Test." Drvna Industrija. 65(2), pp. 99-104. 2014.

DOI: $10.5552 /$ drind.2014.1326

[9] Topper, T. H., El Haddad, M. H. "Fatigue strength prediction of notches based on fracture thresholds." In: 1st International Conference, Stockholm, Vol. 2, EMAS, Warley, U.K, pp. 777-797. 1981.

[10] Rahman, S., Brust, F. W. "Approximate methods for predicting J-integral of a circumferentially surface-cracked pipe subject to bending." International Journal of Fracture. 85(2), pp. 111-130. 1997. DOI: 10.1023/A:1007322018722

[11] Lahlou, M., Ouaomar, H., Mouhib, N., Hachim, A., El Ghorba, M. "Student and Weibull Statistical Study applied on Experimental results of the P265GH Steel used for pressure vessel." International Journal of Advanced Research in Science and Technology (IJARST). 4(6), pp. $402-$ 405. 2015. URL: http://www.ijarst.com/IJARST20140436.html 
[12] Lahlou, M., Hachim, A., Mouhib, N., Ouaomar, H., Rachik, M., El Ghorba, M. "Numerical modeling and analytical validation of stress intensity factor and crack velocity for SENT tensile specimen of P265GH steel material." International Journal of Research (IJR). 2(6), pp. 489-494. 2015. URL: http://edupediapublications.org/journals/index.php/IJR/article/viewFile/2235/2125

[13] CODAP: Code de Construction des Appareils à Pression non soumis à la flame. (CODAP : Code for Construction of unfired Pressure Vessels.), 2005. (in French)

[14] Cast3M, code d'éléments finis, CEA. (Cast3M, finite element code.) [Online]. Available from: http://www-cast3m.cea.fr/ [Accessed: 2013] (in French)

[15] Lahlou, M., Hachim, A., Ouaomar, H,. Mouhib, N., El Ghorba, M. "Procedure for the numerical modeling of the specimen (SENB) using CAST3M calculation code." International Journal of Innovation and Scientific Research. 19(2), pp. 259-266. 2015. URL: http://www.ijisr. issr-journals.org/abstract.php?article=IJISR-15-132-06
[16] Barsoum, R. S. "Further application of quadratic isoparametric finite elements to linear fracture mechanics of plate bending and general shells." International Journal of Fracture. 11(1), pp. 167-169. 1975. DOI: 10.1007/BF00034724

[17] Paris, P., Erdogan, F. "A critical analysis of crack propagation laws." Journal of Basic Engineering. 85(4), pp. 528-533. 1963. DOI: $10.1115 / 1.3656900$

[18] El Ghorba, M. "Evolution of the damage and crack propagation under cyclic loading of A36 steel and aluminum 6351-T6." Memory Master and Applied Science, University of Montreal, 1985. 